\title{
BMJ Open Impact of sensory interventions on the quality of life of long-term care residents: a scoping review
}

\author{
Chantal Backman (D) , ${ }^{1,2,3}$ Melissa Demery-Varin, ${ }^{1}$ Danielle Cho-Young, ${ }^{1}$ \\ Michelle Crick, ${ }^{1}$ Janet Squires ${ }^{1,2}$
}

To cite: Backman C, DemeryVarin M, Cho-Young D, et al. Impact of sensory interventions on the quality of life of long-term care residents: a scoping review. BMJ Open 2021;11:e042466. doi:10.1136/ bmjopen-2020-042466

- Prepublication history and additional material for this paper is available online. To view these files, please visit the journal online (http://dx.doi.org/10. 1136/bmjopen-2020-042466)

Received 06 July 2020 Revised 09 February 2021 Accepted 10 February 2021
D) Check for updates

(c) Author(s) (or their employer(s)) 2021. Re-use permitted under CC BY-NC. No commercial re-use. See rights and permissions. Published by BMJ.

${ }^{1}$ School of Nursing, University of Ottawa Faculty of Health Sciences, Ottawa, Ontario,

Canada

${ }^{2}$ Clinical Epidemiology Program, Ottawa Hospital Research Institute, Ottawa, Ontario, Canada

${ }^{3}$ Care of the Elderly, Bruyère Research Institute, Ottawa, Ontario, Canada

Correspondence to Dr Chantal Backman; chantal.backman@uottawa.ca

\section{ABSTRACT}

Introduction and purpose Residents in long-term care exhibit diminishing senses (hearing, sight, taste, smell or touch). The purpose of this study was to examine the available literature on the impact of sensory interventions on the quality of life of residents living in long-term care settings.

Methods We conducted a mixed-methods scoping review using Arksey and 0'Malley's framework. Seven databases (Medline (Ovid), PubMed (non-Medline-Ovid), CINAHL (EBSCO), Embase (Ovid), Ageline, PsycINFO (Ovid), Cochrane Central Register of Controlled Trials until 1 December 2020) were searched. Two reviewers independently screened the studies for sensory interventions using a two-step process. Eligible studies underwent data extraction and results were synthesised descriptively.

Results We screened 5551 titles and abstracts. A total of 52 articles met our inclusion criteria. Some interventions involved only one sense: hearing $(n=3)$, sight $(n=12)$, smell $(n=4)$ and touch $(n=15)$. Other interventions involved multiple senses $(n=18)$. We grouped the interventions into 16 categories (music programmes, environmental white noise, bright light interventions, visual stimulations, olfactory stimulations, massages, therapeutic touch, tactile stimulations, physical activity plus night-time programmes, pet therapies, various stimuli interventions, Snoezelen rooms, motor and multisensory based strategies, Namaste care, environmental modifications and expressive touch activities).

Conclusion This preliminary review summarised some of the available sensory interventions that will help inform a series of future systematic reviews on each of the specific interventions. The evidence-based knowledge for sensory interventions will also inform a future audit programme for assessing the presence of sensory interventions in longterm care.

\section{INTRODUCTION}

Our population is ageing. According to new data from the UN, by 2050, one in six people worldwide will be over age 65, up from 1 in 11 in 2020. ${ }^{1}$ In Europe and North America, by 2050 , one in four people will be 65 or over, and the number of people 80 and older worldwide is projected to triple by 2050 , from 143 million to 426 million. ${ }^{1}$

\section{Strengths and limitations of this study}

We considered a wide range of sensory interventions published in the literature.

- Only studies that specifically mentioned at least one of the five senses were included.

- The screening and data extraction were performed in duplicate.

- We could have missed evidence of possible interventions because the authors did not specifically mention one of the senses.

As people age, their senses (hearing, sight, taste, smell and touch) decline. ${ }^{23}$ Previous research has associated sensory loss with decreased quality of life in older adults. ${ }^{4-13}$ As the population gets older, many more people will be living in long-term care communities. These sensory impairments are not always considered in the design of these environments.

Many studies have investigated methods of modifying the physical environment to create a more enriching sensory environment for older adults living in long-term care settings. Such interventions have included: adequate lighting, ${ }^{14}$ appropriate environmental temperatures, ${ }^{15}$ removal of unpleasant noises, ${ }^{16}$ presence of pleasant sounds (music $)^{17}$ and installation of multisensory environments including sensory gardens or Snoezelen rooms. ${ }^{18}$ Other studies have focused on sensory interventions such as: physical contact, ${ }^{19-22}$ animal therapy, ${ }^{23}$ aromatherapy and essential oils, ${ }^{24} 25$ and nutrition. ${ }^{26-32}$

Although, research on older adults and sensory decline exists, this is the first review that focuses on the relationship between sensory interventions and the quality of life of residents living in long-term care settings. To our knowledge, no reviews to date have critically analysed the impact of sensory interventions on the quality of life of older adults 
living in long-term care. This study aimed to examine the available literature on the impact of sensory interventions on the quality of life of residents living in long-term care settings. Specific objectives were: (1) to summarise the current knowledge of sensory interventions on the quality of life of residents living in long-term care and (2) to assess the impact of these sensory interventions on quality of life and/or individual concepts of quality of life of residents.

\section{METHODS}

\section{Research design and methodology}

We followed the five-stage process by Arksey and $\mathrm{O}^{\prime}$ Malley ${ }^{33}$ for conducting this scoping review: (1) identify a research question, (2) identify studies relevant to the research question, (3) review and select a subset of studies for inclusion in the final review, (4) chart the information and data for the selected studies and (5) collate, summarise, and present the results. We also adhered to the Preferred Reporting Items for Systematic Reviews, Meta-Analyses extension for Scoping Reviews (PRISMA-ScR) reporting guideline. ${ }^{34}$ The PRISMA-ScR checklist is available in online supplemental table S1.

\section{Patient and public involvement}

No patients involved.

\section{Deviations from the protocol}

Originally, we had planned to conduct a mixed-methods systematic review and had published our methods in a protocol. ${ }^{35}$ However, given the broad nature of the topic and our findings, we decided to first conduct a scoping review that will then guide a future series of focused systematic reviews on each of the sensory interventions identified in this scoping review.

\section{Identify a research question}

Our research question for the scoping review was: What is known from the existing literature about the impact of sensory interventions on the quality of life of residents living in long-term care settings?

\section{Identify studies relevant to the research question}

The search strategy was devised in consultation with a specialist health sciences librarian (JS), and a second health sciences librarian peer reviewed the search strategies using the Peer Review for Electronic Search Strategies. ${ }^{36}$ The following databases were searched from inceptionto 1 December 2020: Medline (Ovid), PubMed (non Medline-Ovid), CINAHL (EBSCO), Embase (Ovid), Ageline, PsycINFO (Ovid) and the Cochrane Central Register of Controlled Trials. The search strategy used in the MEDLINE database is available in online supplemental table S2. No restrictions were applied to language, publication type or year.

Inclusion and exclusion criteria were applied to all studies, enabling a transparent and focused selection of articles of interest.
We included:

1. Studies with older adult residents living in long-term care settings. We adapted the definition of 'older person' depending on the settings where the studies were conducted. For example, the WHO's definition for 'older people' in Africa is 60 years of age or older. ${ }^{37}$ Long-term care settings were defined as: 'domesticstyled environment[s] that provides 24-hour functional support and care for persons who require assistance with activities of daily living and who often have complex health needs and increased vulnerability'. $\left({ }^{38}, \mathrm{P}\right.$ 183)

2. Studies focused on any of the five senses (sight, hearing, taste, touch and smell) implemented by an organisation. Interventions had to be implemented at the facility or unit level and had to include at a minimum one of the five senses. Examples of such interventions include but are not limited to auditory stimulation (used to enhance mood, promote relaxation and cognition), pet therapy (used to reduce agitation and provide social stimulation, particularly in older people with dementia) and modification of the physical layout of the environment (allowing residents to see and smell food as it is being prepared).

3. Studies focused on the following outcomes: healthrelated quality of life or any of the six individual components of quality of life (mental health, energy/ fatigue, emotional well-being, bodily pain, social functioning and satisfaction). Health-related quality of life was defined as 'a multidimensional concept that includes domains related to physical, mental, emotional and social functioning. It goes beyond direct measures of population health, life expectancy, and causes of death, and focuses on the impact health status has on quality of life'. $\left({ }^{39}, \mathrm{P} 1\right)$ The individual components of quality of life were based on the 36-Item Short Form Survey (V.1.0). ${ }^{40}$

4. Randomised and non-randomised studies, controlled before-and-after studies, retrospective or prospective cohort studies, mixed-methods studies and qualitative studies (that included an intervention).

We excluded:

1. Studies combining long-term care and non long-term care populations (eg, acute care, community-dwelling elders) where outcomes were not reported separately by population.

2. Review and select a subset of studies for inclusion in the final review:

All records were exported into Covidence (an online systematic review software $)^{41}$ for removal of duplicates and reference management. We used a two-step process to screen the results of the literature search as follows: (1) title and abstract screening and (2) full-text screening. Screening was performed independently by reviewers (DC-Y, MD-V and MC). Another reviewer (CB) was consulted in the case of inclusion and exclusion conflicts. 


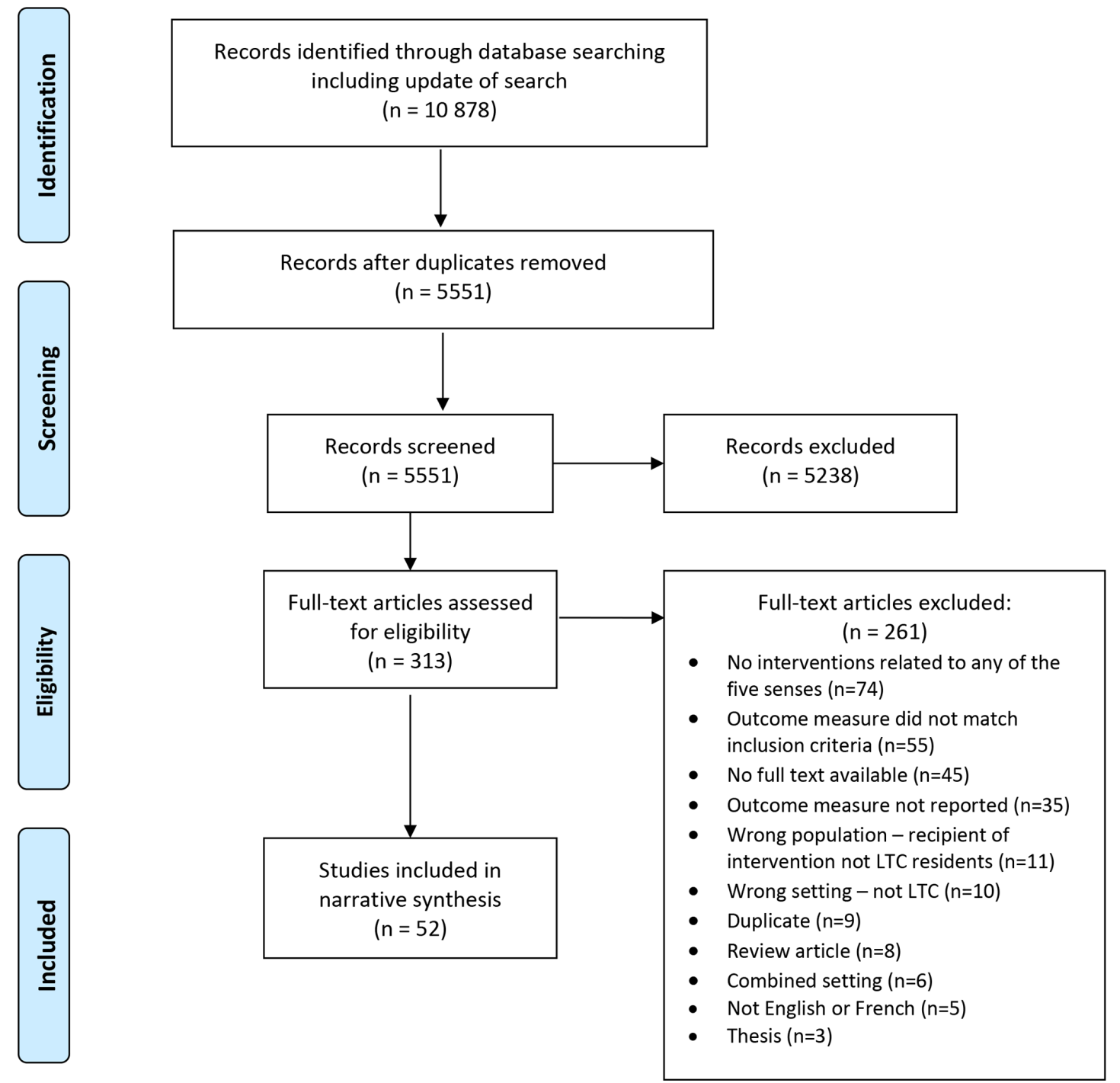

Figure 1 PRISMA flow diagram. PRISMA, Preferred Reporting Items for Systematic Reviews and Meta-Analyses. LTC, longterm care.

\section{Chart the information and data for the selected studies}

Two reviewers (MD-V and DC-Y) independently extracted data from each study using a standardised data abstraction form. Data included: study characteristics (year of publication, authors, country), study objectives, study design, target population, sample size, description of the practice, outcome measures and study results. Authors of the studies were contacted to request missing or additional data where required and were given 30 days to respond.

\section{Collate, summarise and present the results}

The data extracted from the eligible studies were grouped by intervention type and analysed according to each of the senses (hearing, sight, taste, touch, smell). Studies that included more than one sense were aggregated and analysed separately. Due to the wide range of sensory interventions found in the included studies, the results are presented descriptively.

\section{RESULTS}

Study selection

Results of the search strategy were documented within the PRISMA flow diagram (figure 1). We obtained 10878 records from our searches. After removal of duplicates, 5551 records were screened for inclusion. Application of the inclusion criteria to titles and abstracts resulted in the exclusion of 5238 records. We retrieved 313 full-text articles; following application of inclusion criteria to full-text articles, we retained 52 studies $^{182022242542-90}$ (see table 1). Excluded full-text articles $(\mathrm{n}=261)$, and reasons for exclusion are found in online supplemental table S3.

\section{Characteristics of the included studies}

Twenty-three $(44.2 \%)$ of the 52 articles were conducted in the USA $(20,24,45,46,49,54,57,61,62,65,66,68 / 69$, $71,74-77,79,84-87,90)$, four $(7.7 \%)$ in Australia, ${ }^{1822} 2544$ three $(5.8 \%)$ in Turkey, ${ }^{60} 7273$ two $(3.8 \%)$ in Japan, ${ }^{50} 59$ two $(3.8 \%)$ in Canada ${ }^{62}{ }^{67}$ two $(3.8 \%)$ in the Netherlands $[53,88 / 89]$, two $(3.8 \%)$ in Belgium, ${ }^{43} 80$ two $(3.8 \%)$ 


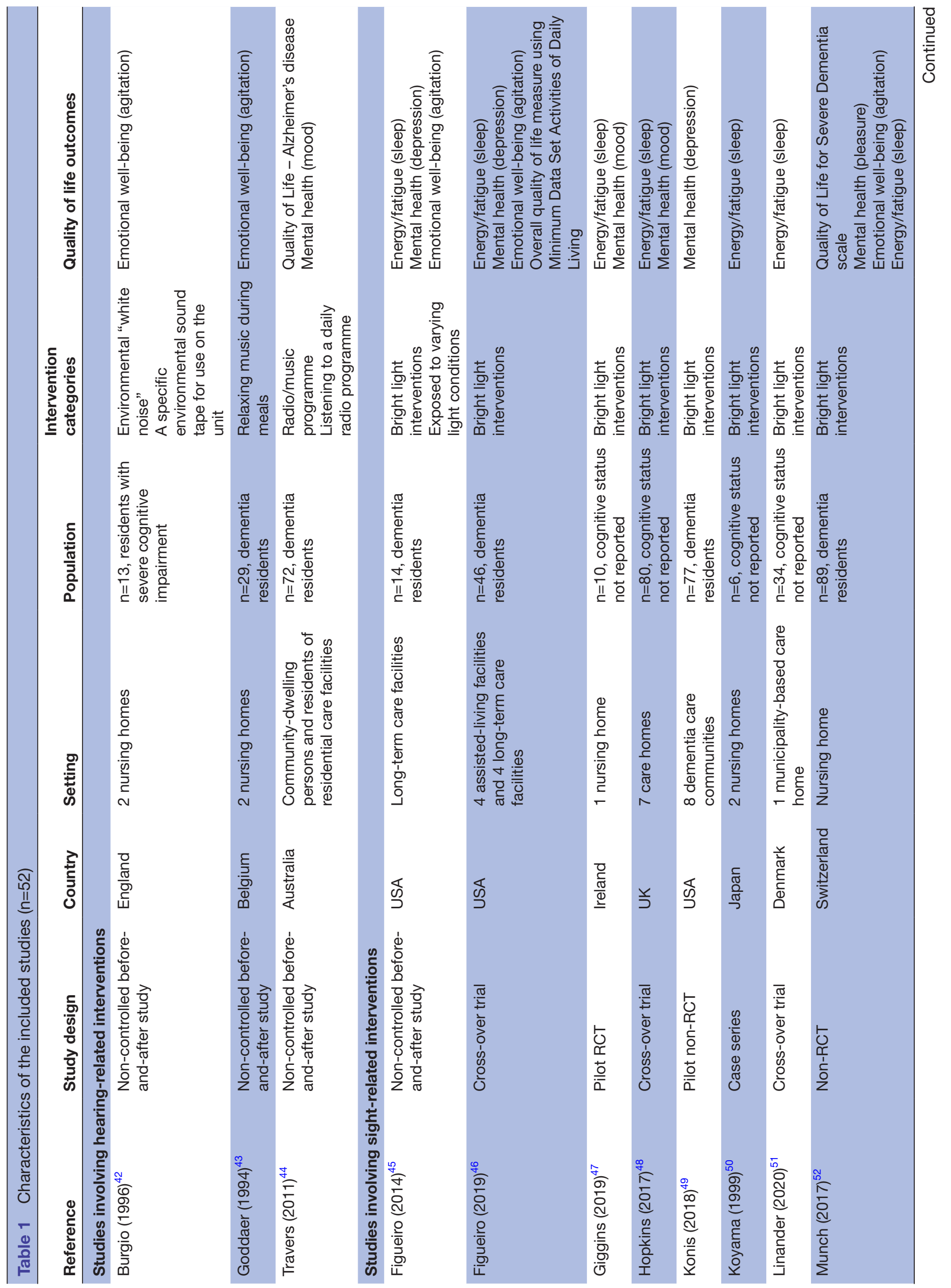




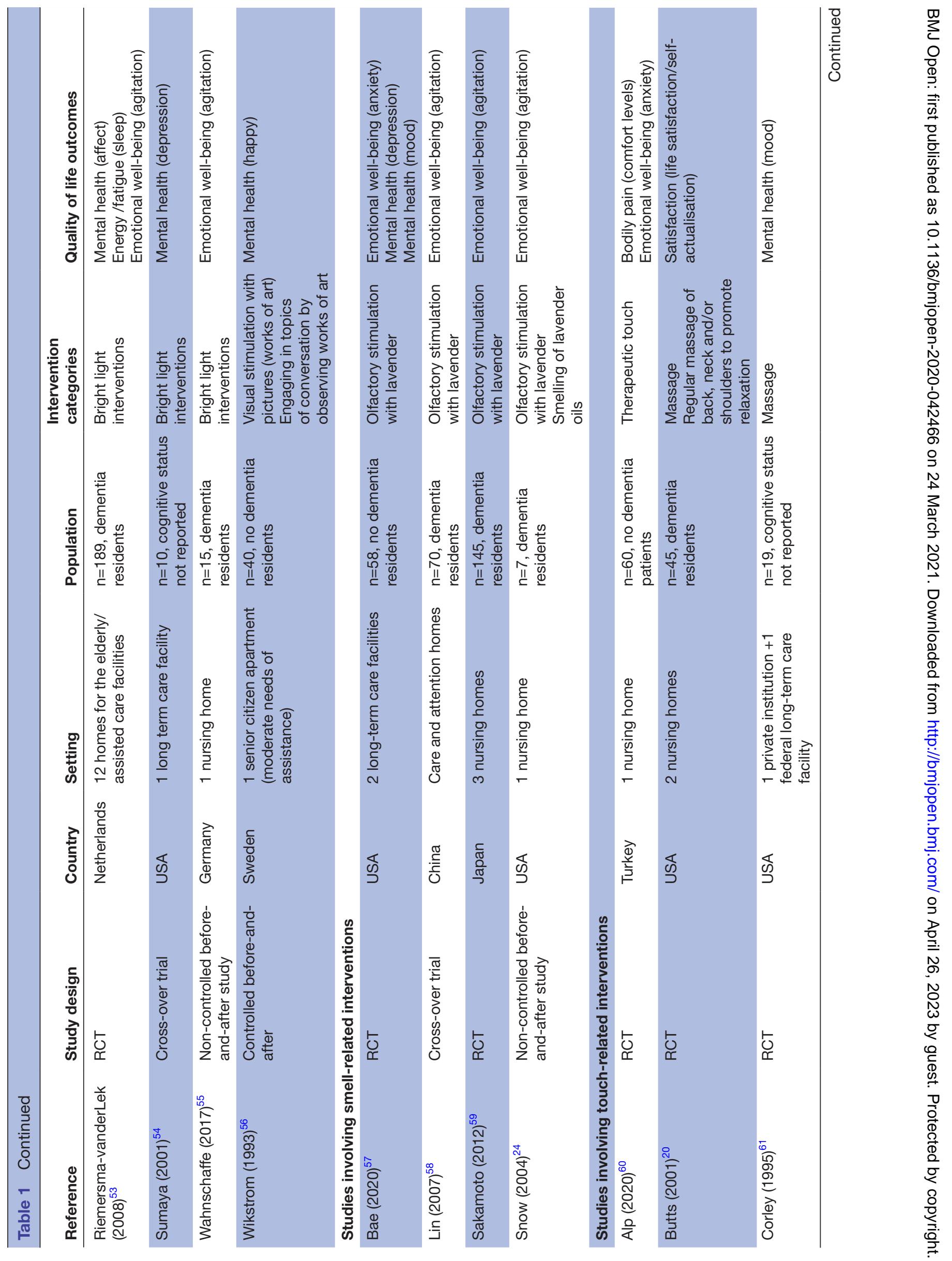




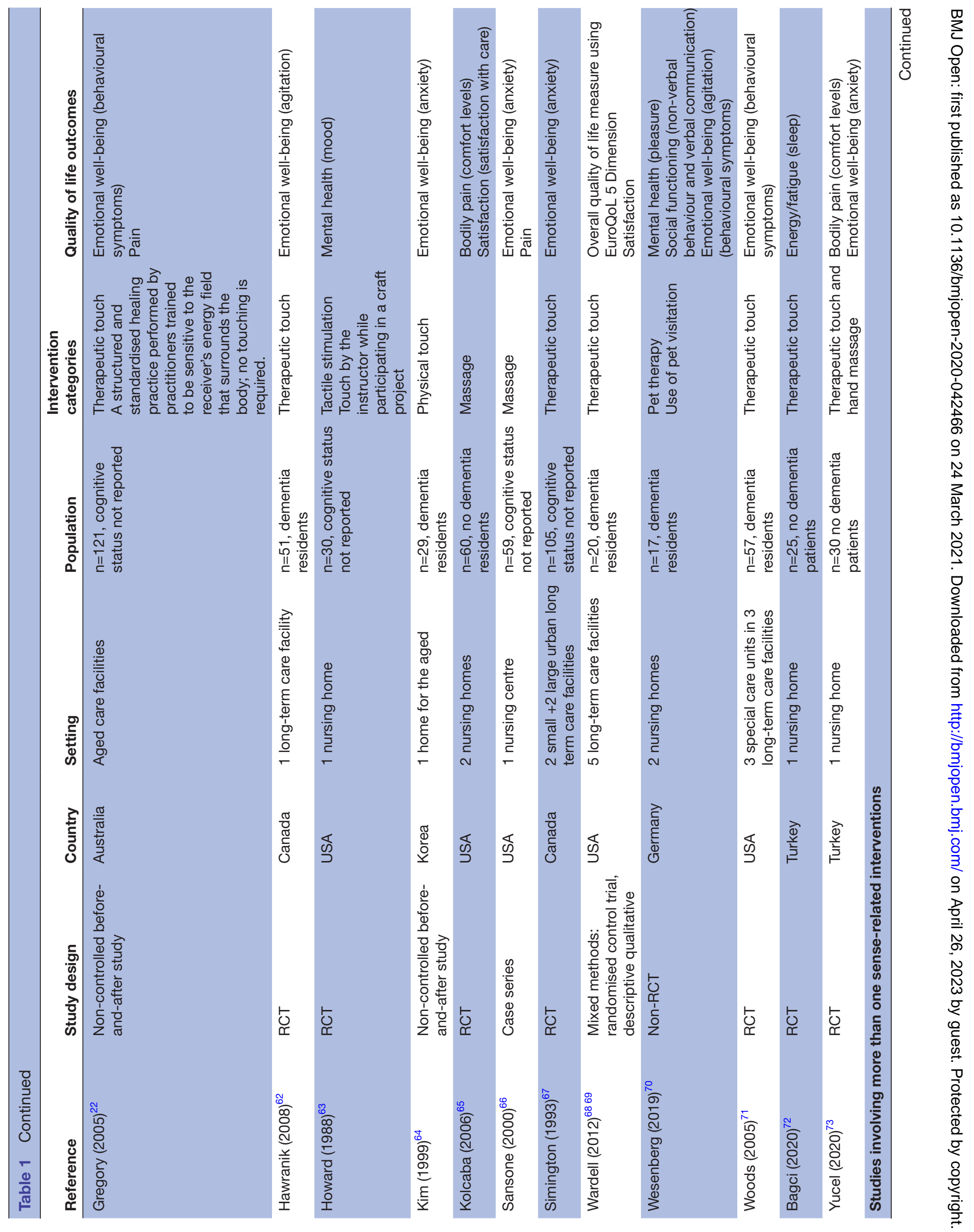




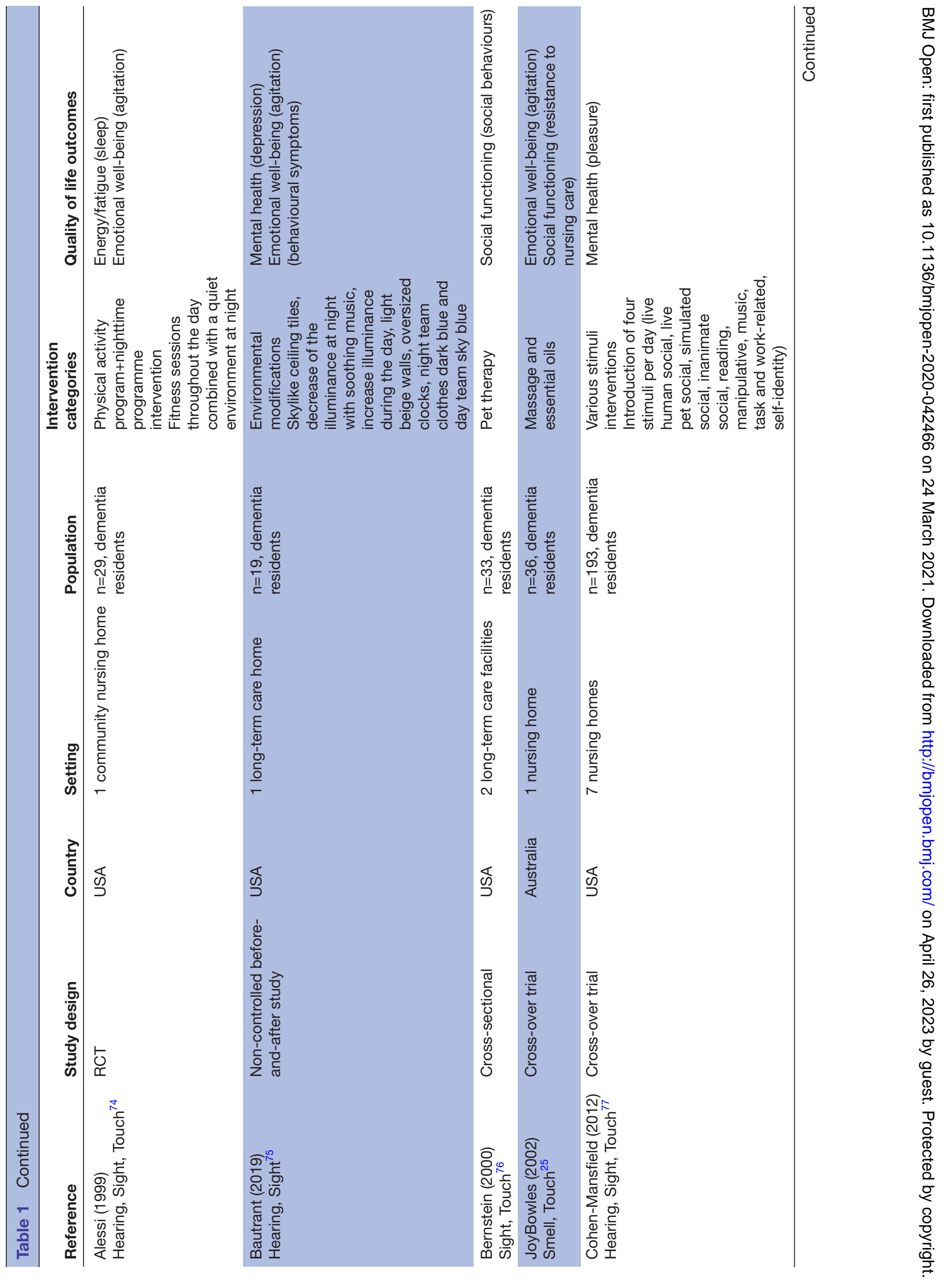




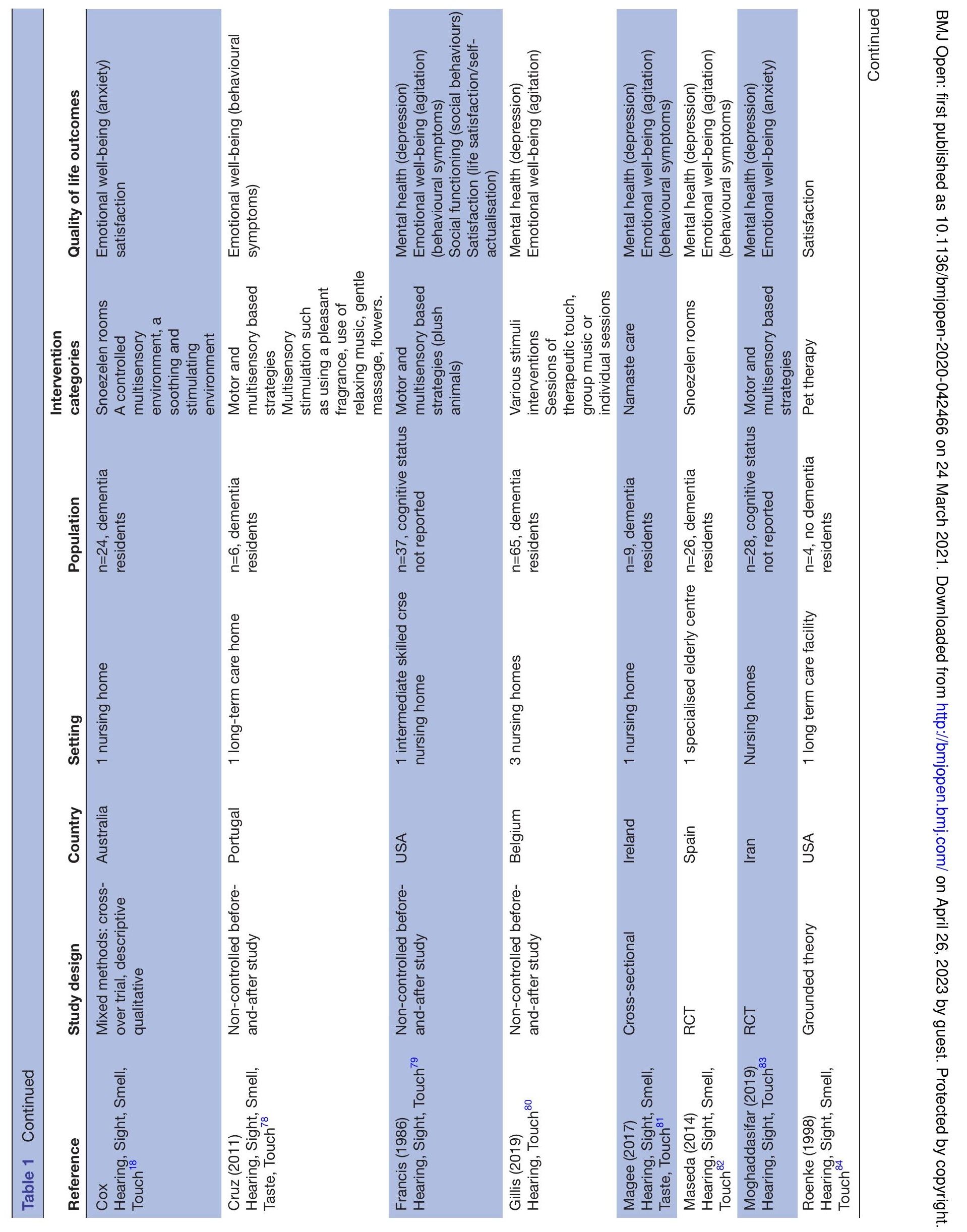




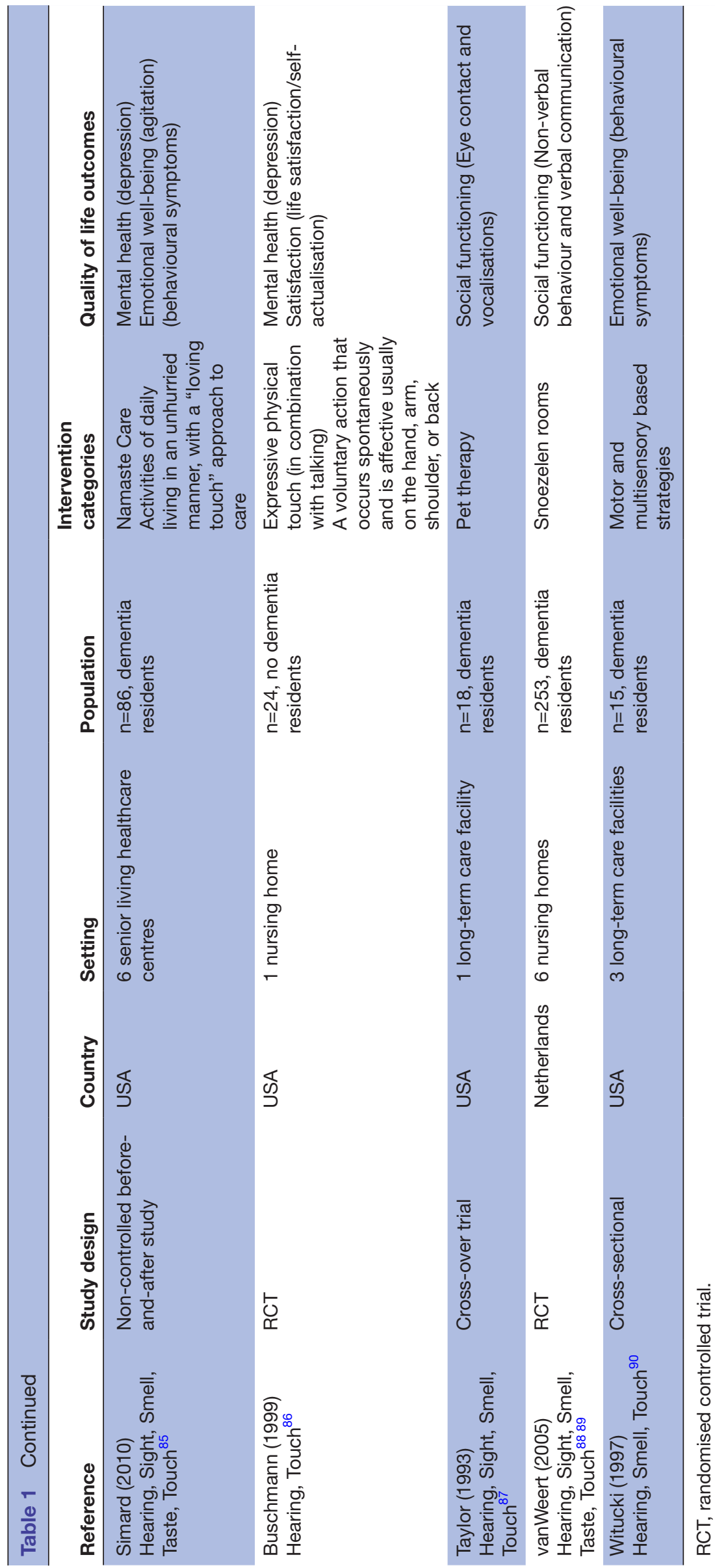

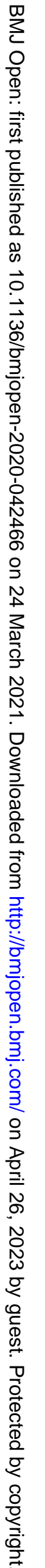


in Germany ${ }^{55} 70$ and one $(1.9 \%)$ each in England, ${ }^{42}$ Ireland, ${ }^{47} \mathrm{UK},{ }^{48}$ Denmark, ${ }^{51}$ Switzerland, ${ }^{52}$ Sweden, ${ }^{56}$ China, ${ }^{58}$ Korea, $^{64}$ Portugal, $^{78}$ Ireland, ${ }^{81}$ Spain $^{82}$ and Iran. ${ }^{83} \mathrm{~A}$ variety of study designs were used including: randomised controlled trials (RCTs) $(n=19) \quad(20,47$, 53, 57, 59-63, 65, 67, 71-74, 82, 83, 86, 88/89), noncontrolled before and after $(\mathrm{n}=13),{ }^{22} 2442-45556475 \quad 78-8085$ cross-over $(\mathrm{n}=8), 2546485154587787$ non-RCTs $(\mathrm{n}=3), 495270$ cross-sectional $(n=3),{ }^{76} 8190$ case series $(n=2),{ }^{50} 66$ mixed methods $(n=2)(18,68 / 69)$, controlled before-and-after $(n=1)^{56}$ and grounded theory $(n=1) .{ }^{84}$ A total of 32 studies $(61.5 \%)$ reported the inclusion of participants with cognitive impairment. The study characteristics are found in table 1 .

\section{Sensory interventions}

Overall, 34 interventions $(n=34)$ targeted only one sense: hearing $(n=3)$, sight $(n=12)$, smell $(n=4)$ and touch $(n=15)$. Eighteen studies $(n=18)$ used a combination of at least two of the senses. No interventions were found specifically addressing taste; however, four interventions involved multiple senses and included taste $(n=4)$. The interventions were grouped into 16 categories (music programmes, environmental white noise, bright light interventions, visual stimulations, olfactory stimulations, massages, therapeutic touch, tactile stimulations, physical activity plus nighttime programmes, pet therapies, various stimuli interventions, Snoezelen rooms, motor and multisensory-based strategies, Namaste care, environmental modifications and expressive touch activities) (see details in table 1).

\section{Outcome measures by senses}

The outcome measures were grouped into categories (overall quality of life, is one category and the individual components of quality of life are represented in six categories: mental health, energy/fatigue, emotional wellbeing, bodily pain, social functioning and satisfaction). Results of the outcomes measures by senses are presented below.

\section{Hearing}

Three studies looked at the sense of hearing and used different interventions. One study ${ }^{44}$ found that their radio programme intervention using the Quality of
Life-Alzheimer's disease significantly improved quality of life for long-term care residents $(n=72)$ ( $p$-value not reported). Their intervention also showed improvement on mental health (mood) ( $p$ value and magnitude not reported). The other two studies showed significant improvement in emotional well-being (see details in table 2).

\section{Sight}

A total of 12 studies looked at the sense of sight and focused on bright light interventions. Of the 12, six $(50 \%)$ studies showed a significant improvement in mental health, and two of those studies also showed a significant improvement in energy/fatigue, and emotional well-being. One other studies showed a significant results in emotional well-being (see details in table 3 ).

\section{Smell}

Four studies looked at the sense of smell and focused on olfactory stimulation with lavender. Two studies showed significant results $(\mathrm{p}=0.04, \mathrm{p}<0.0001)$, while the other two study showed non-significant results for emotional well-being and mental health, respectively. See details in table 4.

Touch

A total of 15 studies looked at the sense of touch and used a variety of interventions. Eight (53\%) studies implemented therapeutic touch, with five studies showing significant improvement, one study showing mixed results for emotional well-being, one showing non-significant improvement in overall quality of life and one showing non-significant improvement in energy/fatigue. Another four (27\%) studies implemented a massage intervention with mixed results. Only one study implemented physical touch, showing a significant results in emotional well-being $(p<0.0001)$, whereas two other studies implemented a tactile stimulation and a pet therapy intervention respectively, but their findings were non-significant (see details in table 5).

Table 2 Interventions for the sense of hearing $(n=3)$

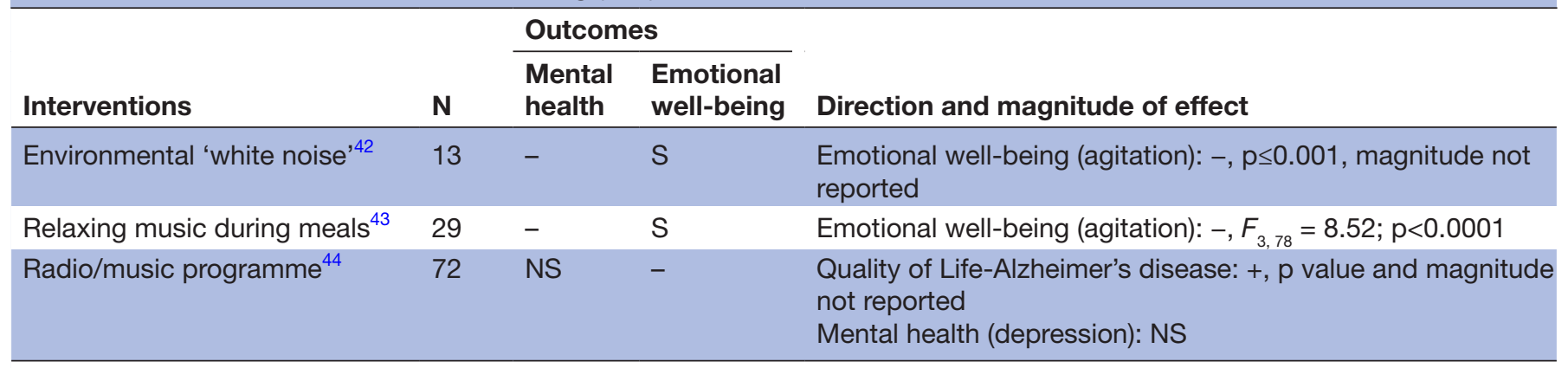

NS, not significant. 
Table 3 Interventions for the sense of sight $(n=12)$

\begin{tabular}{|c|c|c|c|c|c|}
\hline \multirow[b]{2}{*}{ Interventions } & \multirow[b]{2}{*}{$\mathbf{N}$} & \multicolumn{3}{|l|}{ Outcomes } & \multirow[b]{2}{*}{ Direction and magnitude of effect } \\
\hline & & Mental health & $\begin{array}{l}\text { Energy/ } \\
\text { fatigue }\end{array}$ & $\begin{array}{l}\text { Emotional } \\
\text { well-being }\end{array}$ & \\
\hline $\begin{array}{l}\text { Bright light } \\
\text { interventions }\end{array}$ & 46 & $\mathrm{~S}$ & $\mathrm{~S}$ & S & $\begin{array}{l}\text { Energy/fatigue (sleep quality): }+, \mathrm{F} 1,40=14.37 ; \\
p<0.001 \\
\text { Mental health (depression): }-, F 1,40=4.47 ; \\
p=0.04 \\
\text { Emotional well-being (agitation): }-, F 1,40=6.19 ; \\
p=0.02 \\
\text { Overall quality of life measure using MDS-ADL: } \\
F 1,40=1.41 ; p=0.24 \text { NS }\end{array}$ \\
\hline $\begin{array}{l}\text { Bright light } \\
\text { interventions }{ }^{48}\end{array}$ & 80 & NS & NS & - & $\begin{array}{l}\text { Energy/fatigue (sleep): NS } \\
\text { Mental health (mood): NS }\end{array}$ \\
\hline $\begin{array}{l}\text { Bright light } \\
\text { interventions }^{49}\end{array}$ & 77 & S & - & - & $\begin{array}{l}\text { Mental health (depression): }-, p=0.01 \text {, } \\
\text { magnitude not reported }\end{array}$ \\
\hline $\begin{array}{l}\text { Bright light } \\
\text { intervention }\end{array}$ & 6 & - & Mixed & - & Energy/fatigue (sleep): Not reported \\
\hline $\begin{array}{l}\text { Bright light } \\
\text { interventions }{ }^{51}\end{array}$ & 34 & - & NS & - & Energy/fatigue (sleep): NS \\
\hline $\begin{array}{l}\text { Bright light } \\
\text { interventions }^{52}\end{array}$ & 89 & NS & NS & NS & $\begin{array}{l}\text { Quality of Life for Severe Dementia scale: NS } \\
\text { Mental health (pleasure): NS } \\
\text { Emotional well-being (agitation): NS } \\
\text { Energy/fatigue (sleep): NS }\end{array}$ \\
\hline $\begin{array}{l}\text { Bright light } \\
\text { intervention }^{54}\end{array}$ & 10 & S & - & - & $\begin{array}{l}\text { Mental health (depression): }+, p<0.01 \\
\text { magnitude not reported }\end{array}$ \\
\hline $\begin{array}{l}\text { Bright light } \\
\text { interventions }\end{array}$ & 15 & - & - & S & $\begin{array}{l}\text { Emotional well-being (agitation): }-, p \leq 0.05 \text {, } \\
\text { magnitude not reported }\end{array}$ \\
\hline $\begin{array}{l}\text { Visual stimulation } \\
\text { with pictures } \\
\text { (works of art) }^{56}\end{array}$ & 40 & S & - & - & $\begin{array}{l}\text { Mental health (happy): }+, p=0.0001 \text {, magnitude } \\
\text { not reported }\end{array}$ \\
\hline
\end{tabular}

MDS-ADL, Minimum Data Set Activities of Daily Living; NS, not significant.

\section{Multiple senses}

A total of 18 studies looked at multiple senses and used a variety of interventions including a physical activity combined with a nighttime intervention programme $(\mathrm{n}=1)$, a massage intervention $(\mathrm{n}=1)$, various stimuli interventions $(n=2)$, motor and multisensory-based strategies $(n=4)$, Snoezelen rooms $(n=3)$, Namaste care $(n=2)$, expressive physical touch (in combination with talking) $(n=1)$, pet therapy $(n=3)$ and environmental modifications $(n=1)$. For the four studies implementing motor and multisensory-based strategies, three showed significant results. For the three studies implementing Snoezelen rooms, and the three studies implementing pet therapy, all showed mixed results (see details in table 6). 
Table 4 Interventions for the sense of smell $(n=4)$

\begin{tabular}{|c|c|c|c|c|}
\hline \multirow[b]{2}{*}{ Interventions } & \multirow[b]{2}{*}{$\mathbf{N}$} & \multicolumn{2}{|c|}{ Outcomes } & \multirow[b]{2}{*}{ Direction and magnitude of effect } \\
\hline & & $\begin{array}{l}\text { Mental } \\
\text { health }\end{array}$ & $\begin{array}{l}\text { Emotional } \\
\text { well-being }\end{array}$ & \\
\hline Olfactory stimulation with lavender ${ }^{57}$ & 58 & NS & - & Mental health (depression): NS \\
\hline Olfactory stimulation with lavender ${ }^{58}$ & 70 & - & S & $\begin{array}{l}\text { Emotional well-being (agitation): }-, p<0.001 \text {, magnitude } \\
\text { not reported }\end{array}$ \\
\hline
\end{tabular}

NS, not significant.

\section{DISCUSSION}

\section{Key findings}

In this scoping review, we identified 52 primary studies exploring the relationship between sensory interventions and the quality of life of residents living in long-term care settings. Four studies $(44,46,52,68 / 69)$ assessed an overall quality of life measure and 48 studies $(n=48)$ examined individual components of quality of life.

We found that there were many interventions that relate to the five senses. We grouped these interventions into 16 categories as follows: music programmes, environmental white noise, bright light interventions, visual stimulations, olfactory stimulations, massages, therapeutic touch, tactile stimulations, physical activity plus nighttime programmes, pet therapies, various stimuli interventions, Snoezelen rooms, motor and multisensory based strategies, Namaste care, environmental modifications and expressive touch activities. These categories will be helpful to inform the design of a future series of systematic reviews related to the five senses.

In our current scoping review, we identified some promising interventions that showed improvement in one of the quality of life components based on the senses: (1) Hearing: One study implemented a radio/music programme intervention that showed improvement in overall quality of life, ${ }^{44}$ two other studies implementing white noise ${ }^{42}$ and relaxing music during meals, ${ }^{43}$ both showed improvement in emotional well-being, (2) Sight: 6 out of $12(50 \%)$ studies showed an improvement in mental health ${ }^{454649535456}$ and two of these studies also showed an improvement in energy/fatigue and emotional well-being, ${ }^{45} 46$ (3) Smell: Two out of four studies showed a significant improvement in emotional well-being, ${ }^{58} 59$ (4) Touch: 5 of 15 studies (33\%) implementing a therapeutic touch intervention showed a significant improvement in emotional well-being, ${ }^{22} 60677173$ (5) Taste: No interventions were found to address taste specifically. Furthermore, a total of 18 studies examined multiple senses. Of these studies, four studies implemented motor and multisensory-based strategies, three showing significant results, ${ }^{79} 8390$ three studies implemented Snoezelen rooms $(18,82,88 / 89)$ and three studies implemented pet therapy, ${ }^{76487}$ all showing mixed results. Overall, the studies were of poor quality demonstrating the need for further, more robust research in this area.

\section{Strengths and limitations}

Despite the rigorous methods used in this review, there were limitations. First, there was a major limitation in the search strategy. Only studies that mentioned one of the five senses specifically were identified in the search. This was done to increase the sensitivity and specificity of the search; however, the results may not be reflective of all interventions that are designed to impact the senses. For example, pet therapy, or massage therapy were not included as terms in the search strategy. Second, we only searched a few databases, and as such, this review may not contain all the work completed on this topic. Third, since this was a scoping review, the reference lists of included articles as well as grey literature were not hand-searched. Finally, in the analysis, we used a vote counting approach to synthesise the data. Vote counting has its limitations as it does not take into account the difference in weights given to each study and it does not take into account estimates of the effect size. ${ }^{91}$ Thus, a series of systematic reviews for all the sensory interventions identified could be conducted to further explore these areas.

\section{Comparison with previous research}

Although previous studies have looked at sensory decline and decreased quality of life, ${ }^{4-13}$ and at interventions related to the senses, ${ }^{14-32}$ this is the first review specifically looking at sensory interventions for older adults with a general decline of the senses living in long-term care.

Previous work in hospital settings by Maria Ugolini $e t a \ell^{2}$ support the importance of incorporating the five senses in the care of patients. Their proposed model identified the important role that the physical environment has on the healing process of patients and the need for improvement actions focused on the sensory perception of their patients. Similarly, a narrative review by Iyendo $e t a l^{33}$ of 195 studies also acknowledged the importance of the physical hospital environment and its impact on wellness. The authors reported that a calm well-designed hospital interior with natural lighting, 
Table 5 Interventions for the sense of touch $(n=15)$

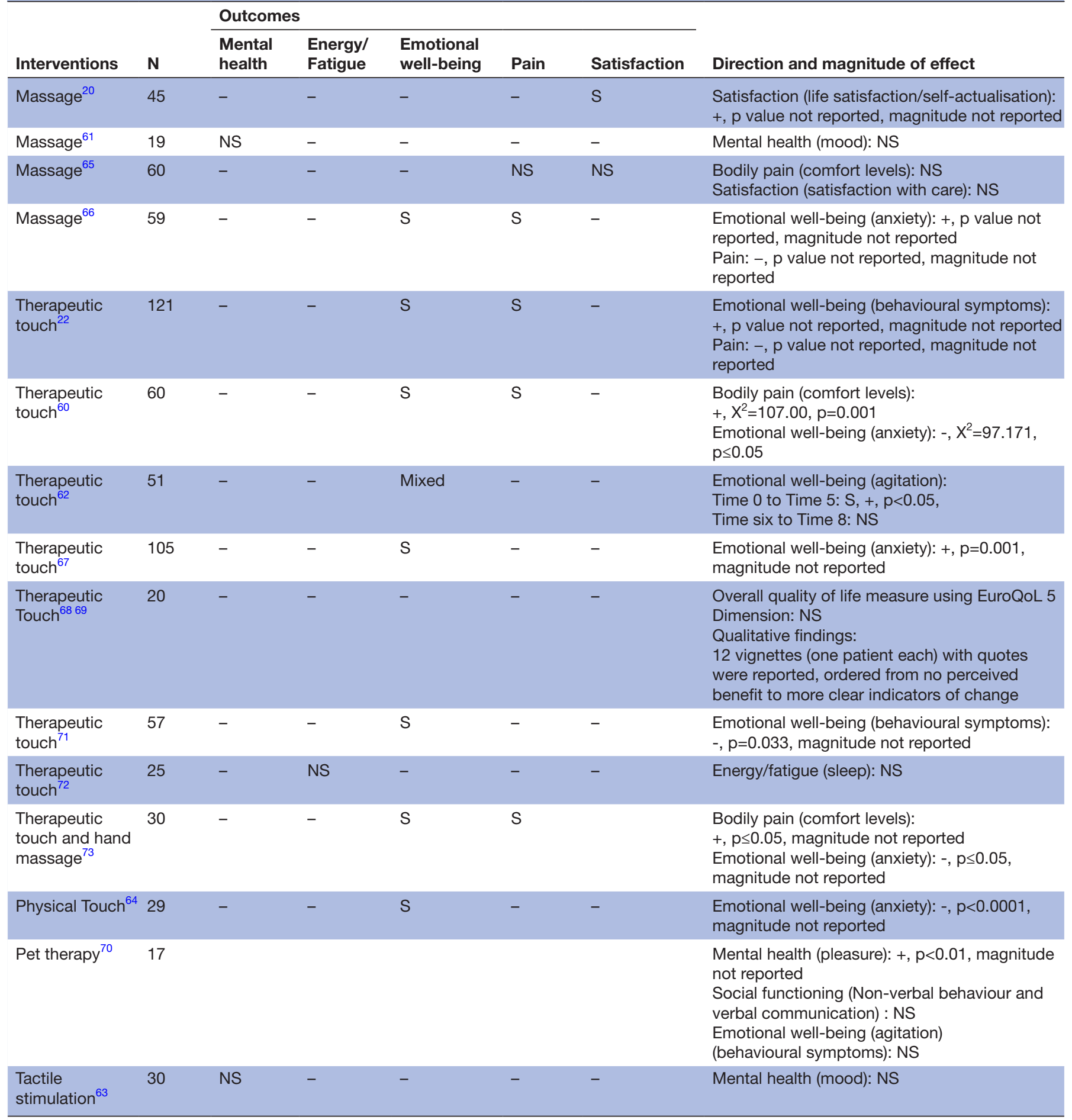

NS, not significant.

landscaped gardens and colourful art can reduce stressful conditions and creates a better healing environment.

Overall, research findings acknowledge the importance of the environment on supporting residents with sensory impairments to perform safely their activities of daily living. A scoping review ${ }^{94}$ of 51 studies in long-term care settings identified key barriers to managing two of the five senses, hearing and vision losses (ie, lack of staff knowledge, poor management of assistive aids, unsuitable environment) and the need to implement best practices. They identified six themes including knowledge, assistive devices, screening tools, external organisations, the environment and cognition. Yet, the implementation of sensory interventions require time and cost to long-term care organisations, which may create some challenges in their broad uptake. Specific guidelines are needed for 
Table 6 Interventions for multiple senses $(n=18)$

\begin{tabular}{|c|c|c|c|c|c|c|}
\hline \multirow[b]{2}{*}{$\begin{array}{l}\text { Interventions } \\
\text { (senses) }\end{array}$} & \multirow[b]{2}{*}{$\mathbf{N}$} & \multicolumn{5}{|c|}{ Outcomes } \\
\hline & & $\begin{array}{l}\text { Mental } \\
\text { health }\end{array}$ & $\begin{array}{l}\text { Energy/ } \\
\text { Fatigue }\end{array}$ & $\begin{array}{l}\text { Emotional } \\
\text { well-being }\end{array}$ & $\begin{array}{l}\text { Social } \\
\text { functioning }\end{array}$ & Satisfaction \\
\hline Massage $^{25}$ & 36 & - & - & $S$ & $S$ & - \\
\hline $\begin{array}{l}\text { Physical activity } \\
\text { program +night- } \\
\text { time programme } \\
\text { intervention }\end{array}$ & 29 & - & $S$ & $S$ & - & - \\
\hline
\end{tabular}

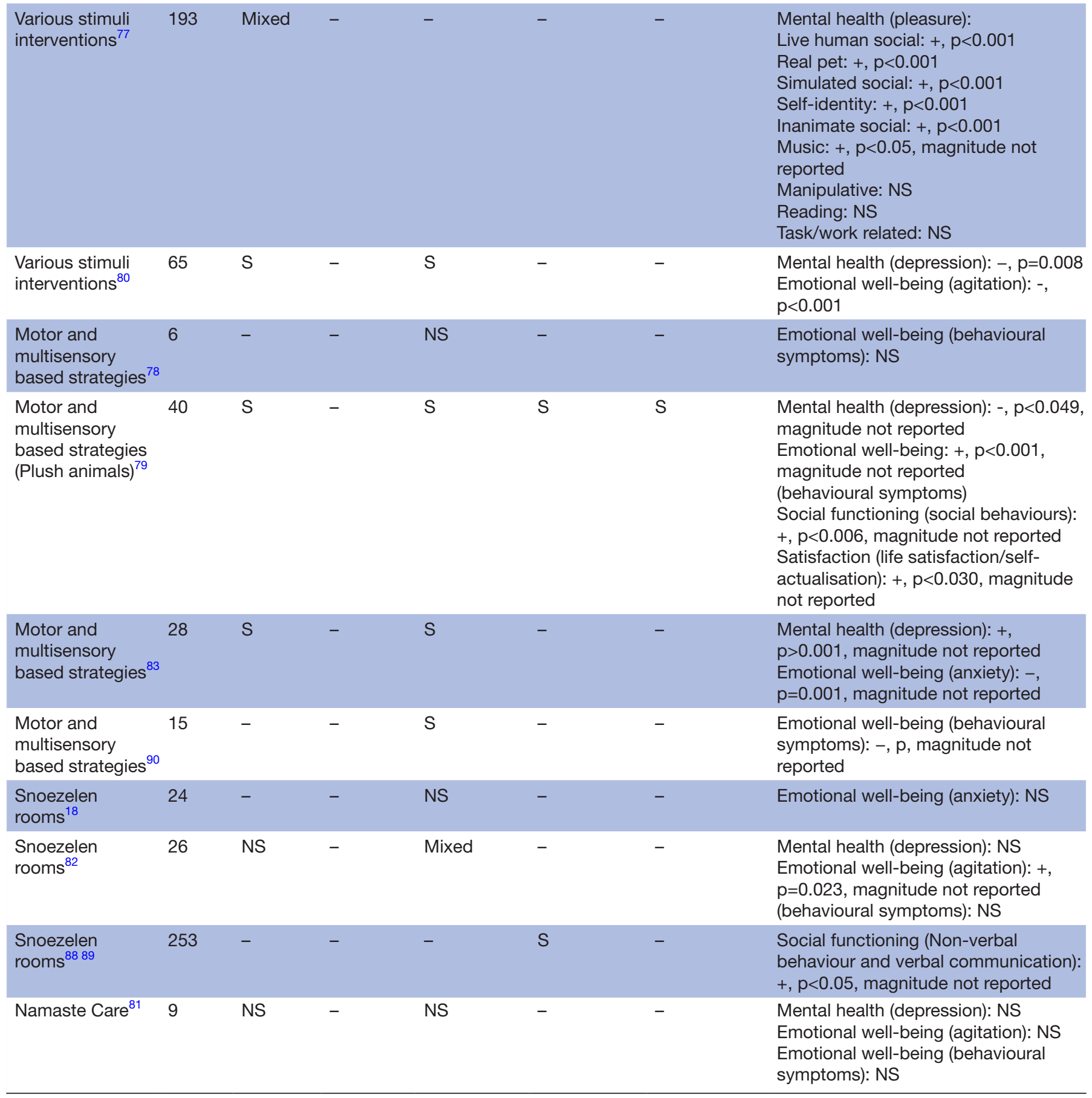

otional well-being (agitation): + $\mathrm{p}=0.0364$, magnitude not reported Social functioning (resistance to nursing care):,$- p=0.0026$, magnitude not reported

Energy/fatigue (sleep):,$+ p=0.045$, magnitude not reported

Emotional well-being (agitation): +, $\mathrm{p}=0.009$, magnitude not reported

Mental health (pleasure):

(

Simulated social:,$+ p<0.00$

Self-identity:,$+ p<0.001$

Music:,$+ p<0.05$, magnitude not

Reading: NS

$\begin{array}{llllll}\text { Motor and } & 40 & \text { S } & - & \text { S } & \text { S }\end{array}$

multisensory magnitude not reported ,$+ \mathrm{p}<0.006$, magnitude not reported Satisfaction (life satisfaction/selfactualisation):,$+ \mathrm{p}<0.030$, magnitude 
Table 6 Continued

\begin{tabular}{|c|c|c|c|c|c|c|c|}
\hline \multirow[b]{2}{*}{$\begin{array}{l}\text { Interventions } \\
\text { (senses) }\end{array}$} & \multirow[b]{2}{*}{$\mathbf{N}$} & \multicolumn{5}{|c|}{ Outcomes } & \multirow[b]{2}{*}{ Direction and magnitude of effect } \\
\hline & & $\begin{array}{l}\text { Mental } \\
\text { health }\end{array}$ & $\begin{array}{l}\text { Energy/ } \\
\text { Fatigue }\end{array}$ & $\begin{array}{l}\text { Emotional } \\
\text { well-being }\end{array}$ & $\begin{array}{l}\text { Social } \\
\text { functioning }\end{array}$ & Satisfaction & \\
\hline $\begin{array}{l}\text { Expressive } \\
\text { physical touch (in } \\
\text { combination with } \\
\text { talking) }\end{array}$ & 24 & $\mathrm{~S}$ & - & - & - & $\mathrm{S}$ & $\begin{array}{l}\text { Mental health (depression): }-, t=-3.07 \text {, } \\
p=0.005 \\
\text { Satisfaction (life satisfaction/self- } \\
\text { actualisation): }+, p<0.004 \text {, magnitude } \\
\text { not reported }\end{array}$ \\
\hline Pet therapy ${ }^{76}$ & 33 & - & - & - & S & - & $\begin{array}{l}\text { Social functioning (social behaviours): } \\
+, \mathrm{p}<0.01 \text {, magnitude not reported }\end{array}$ \\
\hline Pet therapy ${ }^{84}$ & 4 & - & - & - & - & - & $\begin{array}{l}\text { The four themes were: (1) humanness } \\
\text { (the human component) (2) } \\
\text { anticipation and continuity (3) ability } \\
\text { to facilitate reminiscence: (4) social } \\
\text { aspects. }\end{array}$ \\
\hline Pet therapy ${ }^{87}$ & 18 & - & - & - & NS & - & $\begin{array}{l}\text { Social functioning (eye contact and } \\
\text { vocalisations): NS }\end{array}$ \\
\hline $\begin{array}{l}\text { Environmental } \\
\text { modifications }^{75}\end{array}$ & 19 & NS & - & $\mathrm{S}$ & - & - & $\begin{array}{l}\text { Mental health (depression): NS } \\
\text { Emotional well-being (agitation): -, } \\
p=0.039 \text {, magnitude not reported } \\
\text { Emotional well-being (behavioural } \\
\text { symptoms): }-, p<0.026 \text {, magnitude } \\
\text { not reported }\end{array}$ \\
\hline
\end{tabular}

NS, not significant.

designing long-term care homes to support residents with sensory losses, and specifically to improve the quality of life of residents living in long-term care settings.

\section{CONCLUSION}

Understanding sensory interventions in long-term care settings remains a relatively new research topic, and there is a paucity of literature that investigates all five senses. This scoping review summarised some of the available sensory interventions, that will help inform a series of future systematic reviews on each of the specific interventions.

The scoping review findings will inform the development of the preliminary content of an audit tool for long-term care organisations to use in assessing their sensory environment and in determining the relationship between sensory interventions and the quality of life of their residents. These results are relevant for policy makers, decision-makers, clinicians and residents/families in long-term care settings.

Acknowledgements We would like to thank Lindsey Sikora (LS) for developing the search strategy.

Contributors All authors (CB, MD-V, DC-Y, MC and JS) contributed to conceptualising and designing the study. MD-V, DC-Y and MC independently performed screening. MD-V and $D C-Y$ independently performed data extraction. CB performed initial data synthesis and JS refined it. CB drafted the manuscript. All authors (MD-V, DC-Y, MC, JS) critically appraised and edited the manuscript. All authors read and approved the final manuscript. CB is the guarantor of the review.
Funding The authors have not declared a specific grant for this research from any funding agency in the public, commercial or not-for-profit sectors.

Competing interests None declared.

Patient consent for publication Not required.

Provenance and peer review Not commissioned; externally peer reviewed.

Data availability statement All data relevant to the study are included in the article or uploaded as online supplemental information.

Supplemental material This content has been supplied by the author(s). It has not been vetted by BMJ Publishing Group Limited (BMJ) and may not have been peer-reviewed. Any opinions or recommendations discussed are solely those of the author(s) and are not endorsed by BMJ. BMJ disclaims all liability and responsibility arising from any reliance placed on the content. Where the content includes any translated material, BMJ does not warrant the accuracy and reliability of the translations (including but not limited to local regulations, clinical guidelines, terminology, drug names and drug dosages), and is not responsible for any error and/or omissions arising from translation and adaptation or otherwise.

Open access This is an open access article distributed in accordance with the Creative Commons Attribution Non Commercial (CC BY-NC 4.0) license, which permits others to distribute, remix, adapt, build upon this work non-commercially, and license their derivative works on different terms, provided the original work is properly cited, appropriate credit is given, any changes made indicated, and the use is non-commercial. See: http://creativecommons.org/licenses/by-nc/4.0/.

ORCID iD

Chantal Backman http://orcid.org/0000-0001-7431-8159

\section{REFERENCES}

1 United Nations. World population prospects 2019. Available: https:// population.un.org/wpp/

2 Novak M. Aging and society: a Canadian perspective. Nelson, Canada; 2013. 
3 Pohl PS, Dunn W, Brown C. The role of sensory processing in the everyday lives of older adults. OTJR 2003;23:99-106.

4 Fischer ME, Cruickshanks KJ, Klein BEK, et al. Multiple sensory impairment and quality of life. Ophthalmic Epidemiol 2009;16:346-53.

5 Pinto JM, Wroblewski KE, Kern DW, et al. Olfactory dysfunction predicts 5-year mortality in older adults. PLoS One 2014;9:e107541.

6 Wilson RS, Yu L, Bennett DA. Odor identification and mortality in old age. Chem Senses 2011;36:63-7.

7 Wang JJet al. Visual impairment, age-related cataract, and mortality. Arch Ophthal 2001;119:1186-90.

8 Rovner BW, Ganguli M. Depression and disability associated with impaired vision: the movies project. J Am Geriatr Soc 1998;46:617-9.

9 Klaver CCWet al. Age-Specific prevalence and causes of blindness and visual impairment in an older population. Arch Ophthal 1998;116:653-8.

10 Li L, Simonsick EM, Ferrucci L, et al. Hearing loss and gait speed among older adults in the United States. Gait Posture 2013;38:25-9.

11 Genther DJ, Betz J, Pratt S, et al. Association of hearing impairment and mortality in older adults. The Journals of Gerontology Series A: Biological Sciences and Medical Sciences 2015;70:85-90.

12 Schiffman SS, Graham BG. Taste and smell perception affect appetite and immunity in the elderly. Eur J Clin Nutr 2000;54 Suppl 3:S54-63

13 Besné I, Descombes C, Breton L. Effect of age and anatomical site on density of sensory innervation in human epidermis. Arch Dermato 2002;138:1445-50.

14 De Lepeleire J, Bouwen A, De Coninck L, et al. Insufficient lighting in nursing homes. J Am Med Dir Assoc 2007;8:314-7.

15 Mendes A, Papoila AL, Carreiro-Martins P, et al. The influence of thermal comfort on the quality of life of nursing home residents. $J$ Toxicol Environ Health A 2017;80:729-39.

16 Dijkstra K, Pieterse M, Pruyn A. Physical environmental stimuli that turn healthcare facilities into healing environments through psychologically mediated effects: systematic review. J Adv Nurs 2006;56:166-81.

17 Fredriksson A-C, Hellström L, Nilsson U. Patients' perception of music versus ordinary sound in a postanaesthesia care unit: A randomised crossover trial. Intensive and Critical Care Nursing 2009;25:208-13.

18 Cox H, Burns I, Savage S. Multisensory environments for leisure: promoting well-being in nursing home residents with dementia. $J$ Gerontol Nurs 2004;30:37-45.

19 Weisberg J, Haberman MR. A therapeutic Hugging week in a geriatric facility. J Gerontol Soc Work 1989;13:181-6.

20 Butts JB. Outcomes of comfort touch in institutionalized elderly female residents. Geriatr Nurs 2001;22:180-4.

21 Fraser J, Ross Kerr J. Psychophysiological effects of back massage on elderly institutionalized patients. J Adv Nurs 1993;18:238-45.

22 Gregory S, Verdouw J. Therapeutic touch: its application for residents in aged care. Aust Nurs $J$ 2005;12:23-5.

23 Baun MM, Bergstrom N, Langston NF, et al. Physiological effects of human/companion animal bonding. Nurs Res 1984:33:126-9.

24 Snow LA, Hovanec L, Brandt J. A controlled trial of aromatherapy for agitation in nursing home patients with dementia. $J$ Altern Complement Med 2004;10:431-7.

25 Joy Bowles E, Bowles J, Griffiths Q. Effects of essential oils and touch on resistance to nursing care procedures and other dementiarelated behaviours in a residential care facility. International Journal of Aromatherapy 2002;12:22-9.

26 Adams K, Anderson JB, Archuleta M, et al. Defining skilled nursing facility residents' dining style preferences. J Nutr Gerontol Geriatr 2013;32:213-32.

27 Bautista EN, Tanchoco CC, Tajan MG, et al. Effect of flavor enhancers on the nutritional status of older persons. J Nutr Health Aging 2013;17:390-2.

28 Cassens D, Johnson E, Keelan S. Enhancing taste, texture, appearance, and presentation of Pureed food improved resident quality of life and weight status. Nutr Rev 1996;54:S51-4.

29 Hartwell H, Johns N, Edwards JSA. E-menus-Managing choice options in hospital foodservice. Int J Hosp Manag 2016;53:12-16.

30 O'hara PA, Harper DW, Kangas M, et al. Taste, temperature, and presentation predict satisfaction with foodservices in a Canadian continuing-care Hospital. J Am Diet Assoc 1997;97:401-5.

31 Ohno T, Uematsu H, Nozaki S, et al. Improvement of taste sensitivity of the nursed elderly by oral care. J Med Dent Sci 2003;50:101-7.

32 Baur V, Abma T. 'The Taste Buddies': participation and empowerment in a residential home for older people. Ageing Soc 2012;32:1055-78.

33 Arksey H, O'Malley L. Scoping studies: towards a methodological framework. Int J Soc Res Methodol 2005:8:19-32.
34 Tricco AC, Lillie E, Zarin W, et al. PRISMA extension for scoping reviews (PRISMA-ScR): checklist and explanation. Ann Intern Med 2018;169:467-73.

35 Backman C, Crick M, Cho-Young D, et al. What is the impact of sensory practices on the quality of life of long-term care residents? A mixed-methods systematic review protocol. Syst Rev 2018;7:115

36 McGowan J, Sampson M, Salzwedel DM, et al. Press peer review of electronic search strategies: 2015 guideline statement. J Clin Epidemiol 2016;75:40-6.

37 World Health Organization. Proposed working definition of an older person in Africa for the MDS project. Available: http://www.who.int/ healthinfo/survey/ageingdefnolder/en/

38 Sanford AM, Orrell M, Tolson D, et al. An international definition for "nursing home". J Am Med Dir Assoc 2015;16:181-4.

39 Office of Disease Prevention and Health Promotion. Health-Related Quality of Life \& Well-Being. Available: https://www.healthypeople. gov/2020/topics-objectives/topic/health-related-quality-of-life-wellbeing

40 Rand Health Care. 36-Item short form survey (SF-36). Available: https://www.rand.org/health-care/surveys_tools/mos/36-item-shortform/scoring.html

41 Covidence. A Cochrane technology program. Available: https://www. covidence.org/

42 Burgio L, Scilley K, Hardin JM, et al. Environmental "white noise": an intervention for verbally agitated nursing home residents. J Gerontol B Psychol Sci Soc Sci 1996;51:P364-73.

43 Goddaer J, Abraham IL. Effects of relaxing music on agitation during meals among nursing home residents with severe cognitive impairment. Arch Psychiatr Nurs 1994;8:150-8.

44 Travers C, Bartlett HP. Silver memories: implementation and evaluation of a unique radio program for older people. Aging Ment Health 2011;15:169-77.

45 Figueiro MG, Plitnick BA, Lok A, et al. Tailored lighting intervention improves measures of sleep, depression, and agitation in persons with Alzheimer's disease and related dementia living in long-term care facilities. Clin Interv Aging 2014;9:1527.

46 Figueiro MG, Plitnick B, Roohan C, et al. Effects of a tailored lighting intervention on sleep quality, Rest-Activity, mood, and behavior in older adults with Alzheimer disease and related dementias: a randomized clinical trial. J Clin Sleep Med 2019;15:1757-67.

47 Giggins OM, Doyle J, Hogan K, et al. The impact of a cycled lighting intervention on nursing home residents: a pilot study. Gerontol Geriatr Med 2019;5:233372141989745.

48 Hopkins S, Morgan PL, Schlangen LJM, et al. Blue-Enriched lighting for older people living in care homes: effect on activity, Actigraphic sleep, mood and alertness. Curr Alzheimer Res 2017:14:1053-62.

49 Konis K, Mack WJ, Schneider EL. Pilot study to examine the effects of indoor daylight exposure on depression and other neuropsychiatric symptoms in people living with dementia in longterm care communities. Clin Interv Aging 2018;13:1071-7.

50 Koyama E, Matsubara H, Nakano T. Bright light treatment for sleepwake disturbances in aged individuals with dementia. Psychiatry Clin Neurosci 1999:53:227-9.

51 Linander CB, Kallemose T, Joergensen LM, et al. The effect of circadian-adjusted LED-based lighting on sleep, daytime sleepiness and biomarkers of inflammation in a randomized controlled crossover trial by pragmatic design in elderly care home dwellers. Arch Gerontol Geriatr 2020;91:104223.

52 Münch M, Schmieder M, Bieler K, et al. Bright light delights: effects of daily light exposure on emotions, Restactivity cycles, sleep and melatonin secretion in severely demented patients. Curr Alzheimer Res 2017;14:1063-75.

53 Riemersma-van der Lek RFet al. Effect of bright light and melatonin on cognitive and noncognitive function in elderly residents of group care facilities. JAMA 2008;299:2642-55.

54 Sumaya IC, Rienzi BM, Deegan JF, et al. Bright light treatment decreases depression in institutionalized older adults: a placebocontrolled crossover study. J Gerontol A Biol Sci Med Sci 2001;56:M356-60.

55 Wahnschaffe A, Nowozin C, Haedel S, et al. Implementation of dynamic lighting in a nursing home: impact on agitation but not on Rest-Activity patterns. Curr Alzheimer Res 2017;14:1076-83.

56 Wikström B-M, Theorell T, Sandström S. Medical health and emotional effects of art stimulation in old age. Psychother Psychosom 1993;60:195-206.

57 Bae S, Asojo AO. Ambient scent as a positive distraction in longterm care units: theory of supportive design. HERD 2020;13:158-72.

58 Lin PW-ki, Chan W-chi, Ng BF-leung, et al. Efficacy of aromatherapy (Lavandula angustifolia) as an intervention for agitated behaviours in 
Chinese older persons with dementia: a cross-over randomized trial. Int J Geriatr Psychiatry 2007;22:405-10.

59 Sakamoto Y, Ebihara S, Ebihara T, et al. Fall prevention using olfactory stimulation with lavender odor in elderly nursing home residents: a randomized controlled trial. J Am Geriatr Soc 2012;60:1005-11.

60 Alp FY, Yucel SC. The effect of therapeutic touch on the comfort and anxiety of nursing home residents. J Relig Health 2020;7. doi:10.1007/s10943-020-01025-4. [Epub ahead of print: 15 May 2020].

61 Corley MC, Ferriter J, Zeh J, et al. Physiological and psychological effects of back rubs. Appl Nurs Res 1995;8:39-42.

62 Hawranik P, Johnston P, Deatrich J. Therapeutic touch and agitation in individuals with Alzheimer's disease. West J Nurs Res 2008;30:417-34.

63 Howard DM. The effects of touch in the geriatric population. Phys Occup Ther Geriatr 1988;6:35-50.

$64 \mathrm{Kim}$ EJ, Buschmann MT. The effect of expressive physical touch on patients with dementia. Int J Nurs Stud 1999;36:235-43.

65 Kolcaba K, Schirm V, Steiner R. Effects of hand massage on comfort of nursing home residents. Geriatr Nurs 2006;27:85-91.

66 Sansone P, Schmitt L. Providing tender touch massage to elderly nursing home residents: a demonstration project. Geriatr Nurs 2000;21:303-8.

67 Simington JA, Laing GP. Effects of therapeutic touch on anxiety in the institutionalized elderly. Clin Nurs Res 1993;2:438-50.

68 Wardell DW, Decker SA, Engebretson JC. Healing touch for older adults with persistent pain. Holist Nurs Pract 2012;26:194-202.

69 Decker S, Wardell DW, Cron SG. Using a healing touch intervention in older adults with persistent pain: a feasibility study. $J$ Holist Nurs 2012;30:205-13.

70 Wesenberg S, Mueller C, Nestmann F, et al. Effects of an animalassisted intervention on social behaviour, emotions, and behavioural and psychological symptoms in nursing home residents with dementia. Psychogeriatrics 2019;19:219-27.

71 Woods DL, Craven RF, Whitney J. The effect of therapeutic touch on behavioral symptoms of persons with dementia. Altern Ther Health Med 2005;11:66-74.

72 Bağcı H, Çınar Yücel Şebnem. Effect of therapeutic touch on sleep quality in elders living at nursing homes. J Relig Health 2020;59:1304-18.

73 Yücel Șebnem Çınar, Arslan GG, Bagci H. Effects of hand massage and therapeutic touch on comfort and anxiety living in a nursing home in turkey: a randomized controlled trial. J Relig Health 2020;59:351-64.

74 Alessi CA, Yoon EJ, Schnelle JF, et al. A randomized trial of a combined physical activity and environmental intervention in nursing home residents: do sleep and agitation improve? J Am Geriatr Soc 1999;47:784-91.

75 Bautrant T, Grino M, Peloso C, et al. Impact of environmental modifications to enhance day-night orientation on behavior of nursing home residents with dementia. J Am Med Dir Assoc 2019;20:377-81.

76 Bernstein PL, Friedmann E, Malaspina A. Animal-assisted therapy enhances resident social interaction and initiation in long-term care facilities. Anthrozoös 2000;13:213-24.
77 Cohen-Mansfield J, Marx MS, Freedman LS, et al. What affects Pleasure in persons with advanced stage dementia? J Psychiatr Res 2012;46:402-6.

78 Cruz J, Marques A, Barbosa AL, et al. Effects of a motor and multisensory-based approach on residents with moderateto-severe dementia. American J Alzheimers Dis Other Demen 2011;26:282-9.

79 Francis G, Baly A. Plush animals--do they make a difference? Geriatr Nurs 1986;7:140-2.

80 Gillis K, Lahaye H, Dom S, et al. A person-centred team approach targeting agitated and aggressive behaviour amongst nursing home residents with dementia using the senses framework. Int J Older People Nurs 2019;14:e12269.

81 Magee M, McCorkell G, Guille S, et al. Feasibility of the Namaste care programme to enhance care for those with advanced dementia. Int J Palliat Nurs 2017;23:368-76.

82 Maseda A, Sánchez A, Marante MP, et al. Effects of multisensory stimulation on a sample of institutionalized elderly people with dementia diagnosis: a controlled longitudinal trial. Am J Alzheimers Dis Other Demen 2014;29:463-73.

83 Moghaddasifar I, Fereidooni-Moghadam M, Fakharzadeh L, et al. Investigating the effect of multisensory stimulation on depression and anxiety of the elderly nursing home residents: a randomized controlled trial. Perspect Psychiatr Care 2019;55:42-7.

84 Roenke L, Mulligan S. The therapeutic value of the human-animal connection. Occup Ther Health Care 1998;11:27-43.

85 Simard J, Volicer L. Effects of Namaste care on residents who do not benefit from usual activities. Am J Alzheimers Dis Other Demen 2010;25:46-50.

86 Buschmann MT, Hollinger-Smith LM, Peterson-Kokkas SE. Implementation of expressive physical touch in depressed older adults. J Clin Geropsychol 1999;5:291-300.

87 Taylor E, Maser S, Yee J, et al. Effect of animals on eye contact and vocalizations of elderly residents in a long term care facility. Phys \& Ther Geriatr 1994;11:61-71.

88 van Weert JCM, van Dulmen AM, Spreeuwenberg PMM, et al. Effects of snoezelen, integrated in $24 \mathrm{~h}$ dementia care, on nursepatient communication during morning care. Patient Educ Couns 2005;58:312-26.

89 van Weert JCM, van Dulmen AM, Spreeuwenberg PMM, et al. Behavioral and mood effects of snoezelen integrated into 24-hour dementia care. J Am Geriatr Soc 2005;53:24-33.

90 Witucki JM, Twibell RS. The effect of sensory stimulation activities on the psychological well being of patients with advanced Alzheimer's disease. Am J Alzheimers Dis 1997;12:10-15.

91 Grimshaw J, McAuley LM, Bero LA, et al. Systematic reviews of the effectiveness of quality improvement strategies and programmes. Qual Saf Health Care 2003;12:298-303.

92 Maria Ugolini M, Rossato C, Baccarani C. A five-senses perspective to quality in hospitals. The TQM Journal 2014;26:284-99.

93 Iyendo TO, Uwajeh PC, Ikenna ES. The therapeutic impacts of environmental design interventions on wellness in clinical settings: a narrative review. Complement Ther Clin Pract 2016;24:174-88.

94 Andrusjak W, Barbosa A, Mountain G. Identifying and managing hearing and vision loss in older people in care homes: a scoping review of the evidence. Gerontologist 2020;60:e155-68. 